\title{
Thrombospondin-4 (TSP4) gene-modified bone marrow stromal cells (BMSCs) promote the effect of therapeutic angiogenesis in critical limb ischemia (CLI) of diabetic rats
}

\section{Qian Zhang}

Shenzhen Luohu People's Hospital

\section{Tao Wang}

University of Chinese Academy of Sciences shenzhen hospital

Xiangfeng Wu

Mudanjiang Medical University

Ying Wang

shenzhen luohu people's hospital

\section{Xuanqin Wu}

University of chinese academy of sciences shenzhen hospital

\section{Meiling Zhou}

shenzhen luohu people's hospital

\section{Zhu Li}

shenzhen luohu people's hospital

\section{Bing Liu}

shenzhen luohu people's hospital

\section{Feng Zheng}

Dalian Medical University

\section{Xizhuo Sun}

Shenzhen Luohu People's Hospital

Tao Liu ( $\nabla$ tao2020@sohu.com )

Shenzhen Luohu People's Hospital https://orcid.org/0000-0002-1199-0076

\section{Research article}

Keywords: Thrombospondin-4, Bone marrow stromal cells, Angiogenesis, Critical limb ischemia

Posted Date: March 3rd, 2020

DOI: https://doi.org/10.21203/rs.3.rs-15860/v1 
License: (c) (i) This work is licensed under a Creative Commons Attribution 4.0 International License. Read Full License

Version of Record: A version of this preprint was published at Biochemical and Biophysical Research Communications on November 1st, 2020. See the published version at https://doi.org/10.1016/j.bbrc.2020.06.148. 


\section{Abstract}

Background Critical limb ischemia (CLI) is the leading cause of lower limb amputation. Traditional treatments for CLI have limitations. Studies have shown that thrombospondin-4 (TSP4) can promote the growth of neovascularization. In this study, we observed the angiogenesis efficiency of TSP4overexpressing BMSC transplantation in CLI treatment.

Methods The recombinant FT106-tsp4-gfp lentiviral vector plasmid was constructed and transfected into 293FT cells. Primary BMSCs were successfully infected with the tsp4 virus, and TSP4 overexpression was confirmed before TSP4-BMSCs infusion. In vitro, TSP4-BMSCs were co-cultured with human umbilical vein endothelial cells (HUVECs). Vascular endothelial growth factor (VEGF) and transforming growth factor- $\beta$ (TGF- $\beta$ ) secretion were measured in the co-culture supernatants by ELISA. The effect of TSP4-BMSCs on endothelial cell proliferation and migration was detected. Meanwhile, the effects of TSP4-BMSC on the angiogenesis of endothelial cells were tested by tube formation experiment and arterial ring test. In vivo, a rat CLI model was established, and $60 \mathrm{CLI}$ rats were randomly divided into the CLI, BMSC + CLI and TSP4-BMSC + CLI groups. The effect of TSP4-BMSC on angiogenesis was detected by the motor function, immunohistochemistry and immunofluorescence staining assays. Neovascular density was detected by digital substraction angiography (DSA).

Results Our results demonstrated that TSP4-BMSCs obviously increased TSP4, VEGF, Ang-1, MMP9, MMP2 and p-Cdc42/Rac1 expression in endothelial cells. TSP4-BMSCs treatment notably upregulated the TGF- $\beta$ /smad2/3 signal pathway in HUVECs. In vivo, TSP4-BMSCs improved the motor function score of the CLI rats and increased MMP2, MMP9, Ang-1, VEGF and VWF protein expression in tissue of the ischaemic area. Meanwhile, new blood vessels can be observed around the ischemic area after TSP4BMSCs treatment.

Conclusions Our data illustrate that TSP4-BMSCs can promote endothelial cell proliferation, migration, tube formation and the recovery of motor function in diabetic hind limb ischaemic rats. TSP4-BMSCs have better therapeutic effects than BMSCs.

\section{Background}

1. Critical limb ischemia (CLI) is the most advanced stage of arteriosclerosis obliterans (ASO), thromboangiitis obliterans (TAO), and collagen disease-associated vasculitis (CDV) [1]. CLI treatment includes statins, antiplatelet therapy, revascularization, and even amputation to reduce cardiovascular risk factors, morbidity and mortality [2,3]. Currently, the prognosis of CLI patients is very poor, and patients diagnosed with CLI have $25 \%$ to $40 \%$ chance of lower limb amputation and about $20 \%$ mortality, resulting in a serious decline in quality of life [4, 5]. Type 2 diabetes mellitus is associated with CLI characterized by arterial stenosis or occlusion, which severely impedes blood supply to the extremities, increases the risk of amputation and vascular death, and is associated with 
significant cardiovascular morbidity and mortality $[4,6,7]$. Therefore, increasing the formation of new blood vessels is an important way to save ischemic tissue.

2. "Therapeutic angiogenesis" was first proposed by Dr. Michael et al. [8] in 1993. It describes the induction or stimulation of neovascularization for the treatment or prevention of pathological clinical situations characterized by local hypovascularity. Evidence also shows that "clinically normal" healing and tissue regeneration can be improved or accelerated by therapeutic angiogenesis. Traditionally, therapeutic angiogenesis has been achieved by surgical and pharmaceutical methods. In recent years, with the development of the stem cell field, more and more researches has been conducted on therapeutic angiogenesis, which has achieved great progress $[9,10]$.According to the principle that stem cells have multiple differentiation potentials and can provide various angiogenic cytokines, patients' autologous stem cells are isolated and transplanted to the ischaemic site to generate a new capillary network and improve the localized ischaemic symptoms of the patients. Autologous stem cell transplantation for the treatment of CLI mainly includes autologous peripheral blood stem cell transplantation and autologous bone marrow stromal cell (BMSC) transplantation using different stem cell sources. BMSC transplantation has the advantage of rapid recovery after transplantation [11]. At present, the clinical application of autologous BMSCs in transplantation has defects, including a low quantity and low efficiency of angiogenesis, which limit its clinical efficacy in the treatment of CLI [12].

3. Thrombospondin-4 (TSP4) is a member of the thrombospondin family that includes 4 other proteins (TSP1, TSP2, TSP3, and TSP5) [13], which are new proangiogenic extracellular matrix (ECM) proteins. TSP4 influences multiple extracellular responses in vitro that translate into enhanced blood vessel formation in vivo [14]. Therefore, in this study, we evaluated whether TSP4 overexpression in BMSCs could promote angiogenesis and further improve the efficacy of BMSC transplantation for CLI treatment.

\section{Results}

\section{Characterization of cultured BMSCs}

As illustrated in Fig. 1a, from passage 2, the cells became uniform and grew in whirlpool, radial, or parallel patterns. As shown in supplemental Fig. 1, we chose passage 3 of the cells to characterize the BMSCs by flow cytometry analysis. The results indicated that $98.34 \%$ and $99.88 \%$ of the cells were CD44and CD90-positive, respectively (both are characteristic BMSC surface markers), 4.81\% were CD34positive (a haematopoietic stem cell marker), and $1.81 \%$ were CD45-positive (a lymphocyte antigen). The flow cytometry results demonstrated that our primary BMSCs were highly purified.

\section{Construction of the FT106-tsp4-gfp plasmid and expression of the TSP4 target protein in BMSCs}

Fig. $1 \mathrm{~b}$ displays the recombinant FT106-tsp4-gfp lentiviral plasmid map. The objective bands were distinctly observed at $6411 \mathrm{bp}, 3110 \mathrm{bp}$ and $908 \mathrm{bp}$ after agarose gel electrophoresis of PCR products of the transfected recombinant FT106-tsp4-gfp lentiviral plasmid-positive clones. The band sizes were in 
agreement with the expected results. The sequencing results were completely in agreement with the given tsp4 gene sequence, which suggested that the recombinant FT106-tsp4-gfp lentiviral plasmid was successfully constructed (Fig. 1c). The transfection efficiency of $g f p$-positive 293FT cells was evaluated $48 \mathrm{~h}$ after transfection with the recombinant FT106-tsp4-gfp plasmid. The percentage of $g f p$-positive cells was $91.25 \% \pm 0.0078$, which showed that the transfection was successful (Fig. 1d). The infection efficiency of the recombinant lentiviral vector $g f p$-positive cells was measured $72 \mathrm{~h}$ after BMSCs were infected with the recombinant lentiviral vector. The percentage of $g f p$-positive cells was $65.49 \% \pm 0.0145$, which showed that the infection was successful (Fig. 1e). The Western blotting results showed that TSP4 expression was obviously higher in the TSP4-BMSCs than in the normal BMSCs $\left({ }^{*} p<0.01\right)$ (Fig. 1f-g). Fluorescent staining indicated that the TSP4 protein was expressed in the TSP4-BMSCs and was mainly present in the cytoplasm (Fig. $1 \mathrm{~h}$ ). The above results indicated that tsp 4 gene fragments were inserted into the BMSCs and that the TSP4 protein was expressed both intra- and extracellularly.

\section{TSP4-BMSCs promoted HUVEC migration and angiogenesis}

The ELISA data showed that more TSP4 was secreted by HUVECs in the TSP4-BMSC group than in the BMSC group ( $\left.{ }^{*} p<0.05\right)$. TSP4 and TGF- $\beta$ secretion by the HUVECs was also increased by BMSC treatment compared to that of the control group $\left({ }^{*} p<0.05\right)$. Furthermore, the VEGF, TGF- $\beta$ and TSP4 levels were increased following incubation of the TSP4-BMSCs with HUVECs compared with that of the control group at $48 \mathrm{~h}\left({ }^{* *} p<0.01,{ }^{*} p<0.05\right)$ (Fig. 2a-c). To elucidate the role of TSP4-BMSCs in the induction of angiogenesis, we performed the arterial ring and tube formation assays in cultured endothelial cells. The quantified results for tube length and tubular branch points showed that angiogenesis was significantly improved by TSP4-BMSC treatment compared with those of the control group at $48 \mathrm{~h}\left({ }^{* *} p<0.01\right)$. The circumference of the arterial ring in the TSP4-BMSC group was also significantly longer than that of the BMSC group $\left({ }^{*} p<0.01\right)$. (Fig. $\left.2 \mathrm{~d}-\mathrm{g}\right)$. Because the proliferation and migration of HUVECs are the key processes involved in angiogenesis, we also assessed whether the TSP4-BMSCs mediated proliferation and migration using the wound healing test. The results showed that the TSP4-BMSCs significantly increased HUVEC proliferation and migration in the control group at $24 \mathrm{~h}$ $(* x<0.01)($ Fig. $2 \mathrm{~h}-\mathrm{i})$.

\section{TSP4-BMSCs enhanced the expression of angiogenic factors in HUVECs}

Western blotting analysis was used to quantify the protein expression levels of angiogenic factors derived from HUVECs incubated with conditioned medium at $48 \mathrm{~h}$. Fig. 3a-b showed that TSP4 expression was significantly higher in the TSP4-BMSC group than in the control and BMSC groups ( $* * p<$ 0.01). Treatment with the TSP4-BMSCs significantly increased VEGF, Ang-1, MMP9 and MMP2 expression compared with treatment with BMSCs alone and the control (**p<0.01). Treatment with TSP4-BMSCs also markedly enhanced phosphorylated Cdc42/Rac1 expression compared with that of the other two groups after $48 \mathrm{~h}$ of incubation $(* * p<0.01)($ Fig. $3 a-b)$. The above results illustrated that TSP4-BMSCs might have an additive effect on improvement of angiogenic factor expression in HUVECs. 
To test whether TSP4-BMSC treatment of HUVECs could activate the TGF- $\beta / \mathrm{smad} 2 / 3$ signalling pathway, we investigated the activation status of TGF- $\beta /$ smad2/3 by Western blotting. Fig. $3 c-d$ indicated that smad2/3 phosphorylation and TGF- $\beta$ expression were significantly higher in the TSP4-BMSC group than in the BMSC and control groups ( $* * p<0.01$ ). However, the increase in the TGF- $\beta$ and $p$-smad $2 / 3$ levels was abrogated by the presence of SIS3 (a smad2/3 inhibitor) $(* * p<0.01)$, suggesting that the TSP4BMSCs promoted angiogenic factor secretion via the TGF- $\beta /$ smad $2 / 3$ signalling pathway. Together, these results suggest that TSP4-BMSCs enhance the expression of angiogenic factors via activation of the TGF- $\beta /$ smad $2 / 3$ pathway more significantly than treatment with BMSCs alone.

\section{Establishment of the CLI model and TSP4-BMSC treatment improved motor function}

The blood glucose level of the rats began to increase from $7.24 \pm 0.70$ to $25.52 \pm 5.30 \mathrm{mmol} / \mathrm{L}$ from the first day after the STZ injection and remained at 25-32 mmol/L (Fig. 4a). On the first day after model construction, claudication was observed in the CLI model Meanwhile, the hind limb angle was large compared with that of the normal rats in a static state $\left({ }^{*} p<0.05\right)$ (Fig. $\left.4 \mathrm{~b}-\mathrm{c}\right)$, and the motor function score was significantly lower than that of the normal rats ( $\left.{ }^{* *} p<0.01\right)$ (Fig. $4 \mathrm{~d}$ ). At 14 days after the operation, ischaemic necrosis of the ischaemic side hind limb was observed, showing gangrene lesions (Fig. 4f). To evaluate whether TSP4-BMSC treatment could attenuate sport injuries caused by hind limb ischaemia, the motion functional test BBB locomotor rating scale was performed. As observed in Fig. 4e, the motor function scores in the TSP4-BMSC + CLI group began to increase from day 7 compared with those in the CLI and BMSC + CLI groups, and the increasing tendency continued to the 28th day. In addition, the motor function scores in the TSP4-BMSC + CLI group were notably higher than those in the CLI group at 7, 14 and 28 days $(* x p<0.01, * p<0.05)$. These data indicated that TSP4-BMSC treatment promoted motor function recovery.

\section{TSP4-BMSCs increased angiogenesis in the ischaemic areas of the rats}

Our immunohistochemical staining shown in Fig. 5a-f indicated that MMP2, MMP9 and Ang-1 expression was more distinct in the TSP4-BMSC + CLI group than in the other groups $(* * p<0.01)$ and that expression in the BMSC + CLI group was significantly higher than that in the CLI group ( ${ }^{*} p<0.01$ ). As an important angiogenic factor, VEGF plays a primary role in facilitating angiogenesis. The quantitative analysis of the fluorescent immunostaining images suggested that VEGF expression was more significant in the TSP4-BMSC + CLI group than in the BMSC + CLI and CLI groups $(* * p<0.01)$ and that BMSC treatment obviously increased VEGF expression compared with that of the CLI group $(* * p<0.01)$ (Fig. 5g-h). As a marker of endothelial cells, vWF expression was more distinguishable in the TSP4-BMSC $+\mathrm{CLI}$ group than in the other groups (**p $<0.01$ ), and expression in the BMSC + CLI group was notably higher than that in the CLI group in our immunofluorescence assay $\left({ }^{*} p<0.01\right)($ Fig. $5 \mathrm{i}-\mathrm{j})$. These results illustrated that TSP4-BMSC treatment dramatically increased VEGF and vWF expression in the ischaemic area. The data of DSA shown that vascular density and blood supply area near the ischemic area in the TSP4-BMSC + CLI group was significantly higher than that in the BMSC + CLI and CLI groups $(* * p<0.01$, * $p<0.05$ ) (Fig. 6). 


\section{Discussion}

1. Critical limb ischemia (CLI) is the leading cause of lower limb amputation. Most CLI patients suffer from diabetes or chronic renal failure or both [17]. Increased plasminogen activator inhibitor and von Willebrand factor in the blood circulation of diabetic patients leads to the increase of fibrinase activity and the decrease of prostaglandin I2 (PGI2), which leads to the increase of vasoconstriction/diastolic dysfunction and platelet adhesion and aggregation, thus triggering the occurrence of thrombosis in diabetic patients [18]. In addition, hyperglycemia in the blood circulation leads to an increase in terminal glycosylation products, which easily binds to specific receptors on vascular endothelium, leading to endothelial dysfunction [19]. Vascular endothelial cells can synthesize and secrete vasoactive substances, such as ET-1 and NO, to regulate the contractile/diastolic function of vascular smooth muscle. The terminal glycosylation product bind to vascular endothelial cells, resulting in dysfunction of endothelial cell secretion, imbalance of NO and ET-1 secretion, inhibition of active factors in vascular wall and circulating blood, and make the hypercoagulability of circulatory system [19]. Specifically, diabetic CLI patients should undergo revascularization immediately because the 5-year survival rate in these patients is reported to be as low as $25 \%$, and diabetes is associated with increased risk of amputation and repeat revascularization procedures [17]. Conventional endovascular treatment suggests balloon angioplasty or bare metal stenting as a rescue strategy in the case of residual stenosis or flowlimiting dissection. However, diabetes mellitus and chronic renal failure contribute to the formation of aggressive, hard atherosclerotic plaques with marked calcifications that are resistant to balloon dilation, reducing the possibility of adequate acute lumen dilation with conventional balloon angioplasty [17].

2. Isner et al. [20] reported the efficacy of gene therapy in using vascular endothelial growth factor plasmids to promote angiogenesis, and thus therapeutic angiogenesis has potential prospects for CLI patients. Potential cell therapies are based on the stimulation of angiogenesis with extracellular or cellular components, including endothelial progenitor cells and stem cells [21-23]. Most of these therapies use bone marrow-derived cells. In a clinical trial, Tateishi-Yuyama et al. attempted to use Therapeutic Angiogenesis by Cell Transplantation (TACT) study to implant autologous bone-marrow derived monocytes (BM-MNC) intramuscularly, and the results showed that the values of percutaneous oxygen pressure, resting pain, ankle-brachial index and pain-free walking time of CLI patients were significantly improved after cell transplantation. This angiogenic cell therapy can induce long-term improvements in limb ischemia, extending amputation-free intervals and survival rates. TACT trial demonstrated the efficacy and safety of autologous BM-MNC implantation in the treatment of CLI patients [24-26]. In 2018, a study of 345 CLI patients for TACT trial to assess the long-term safety and clinical outcomes of therapeutic angiogenesis. The results confirmed that autologous BM-MNC treatment is clinically feasible and safe, especially in the case of TAO or CDV [27]. In China, a 10-year study on autologous BM-MNC treatment in CLI patients with thromboangiitis obliterans has shown that BM-MNC treatment is safe and effective. BM-MNC treatment significantly improved amputation-free survival rate. The 10-year amputation-free survival rate of CLI patients 
was $85.3 \%$. In addition, there were no cases of retinopathy or cancer. These data demonstrate the long-term safety and efficacy of autologous BM-MNC in the treatment of CLI patients [28].

3. Bone marrow-derived stromal/stem cells (BMSCs) are a type of mesenchymal stem cell that has been extensively characterized in terms of their multipotency [29]. In addition to their ability to differentiate, administration of BMSCs can also increase angiogenesis. Studies have shown that BMSC transplantation induces a significant increase in the blood vessel density in the ischaemic boundary zone (IBZ) of rats [30-32]. This result indicates that MSC transplantation noticeably facilitates angiogenesis in the border area of the damage, thereby contributing to metabolic improvement in the ischaemic zone [33]. Although the defined mechanism of BMSC treatment for angiogenesis is unknown, at present most experimental results indicate that the therapeutic effect on angiogenesis is probably relevant to the paracrine effect of BMSCs, which facilitate the secretion of trophic factors, proteases and chemokines, such as VEGF, stem cell homing factor (SDF1), hypoxia inducible factor-1 (HIF-1) and Ang-1[31, 34]. In clinical treatment, a patient's autologous BMSCs are isolated, amplified and then transplanted into the lower ischaemic extremity; these cells gradually differentiate and form new capillaries to improve and restore blood flow to the lower extremity. New blood vessels can be grown to treat CLI after 3-6 months. Since BMSCs are autologous, there is no ethical controversy and no immune rejection, which ensure the safety of clinical application.

However, the bone marrow mesenchymal stem cell content is approximately $0.001 \%$ to $0.01 \%$ of the number of monocytes in bone marrow in practical application. Therefore, a large amount of marrow is needed for clinical treatment, and the age, physical condition and psychological acceptance of the patients are highly relevant factors. At the same time, the survival rate of BMSCs after

transplantation and the rate of angiogenesis reduction due to changes in the microenvironment, such as high glucose, oxidative stress and hypoxia, greatly limit the therapeutic effect of stem cell transplantation. Therefore, how to improve the survival and differentiation of BMSCs in ischaemic tissue, increase the secretion of local tissue growth factors, and improve the efficiency of promotion of angiogenesis by BMSCs are the main problems to be solved in the clinical application of BMSCs for the treatment of CLI .

4. Thrombospondins are multifunctional matricellular proteins that interact with numerous receptors and other binding partners to induce responses in a wide variety of cell types, including vessel wall and circulating blood cells $[13,35]$. The influence of thrombospondins on cellular responses, such as migration, adhesion and proliferation, of vascular cells imply that they may play a significant role in atherogenesis. The family comprises thrombospondins 1-5, which have a stabilizing effect on atherosclerotic plaques and are often relevant to familial premature cardiovascular disease, myocardial infarction [36] and atherosclerosis [37]. Thrombospondin-4 (TSP4) belongs to a group of matricellular ECM proteins that do not provide structural support, such as with collagens or elastins, but instead regulate cell-matrix interactions and the functional responses dependent on these interactions, including adhesion, migration, apoptosis, proliferation, and ECM remodelling/fibrosis $[13,38-44]$. Remodelling of the ECM in the vascular wall initiates and defines the development of cardiovascular disease, diabetic complications, tumour growth, and many other devastating chronic diseases. Remodelling and growth of blood vessels is guided and regulated by matricellular ECM 
proteins, which signal through surface receptors to control numerous vascular cell responses.

Pluskota et al.[43] found that TSP4 created a microenvironment rich in pro-atherogenic stimuli and ripe for lesion development, all of which strongly supported the importance of TSP4 in cardiovascular pathology.

5. In this study, a TSP4-BMSC recombinant plasmid was constructed by gene engineering and used to infect BMSCs via a lentivirus. BMSC growth and proliferation and expression of the target protein TSP4 were observed after infection. The flow cytometry results showed that TSP4-overexpressing BMSCs still had characteristics of stem cells. The Western blotting and ELISA results showed that TSP4 could be stably expressed in BMSCs, and immunofluorescence staining showed that TSP4 was mainly distributed in the cytoplasm and nucleus. To further investigate the effect of TSP4BMSCs on endothelial cells, TSP4-BMSCs and HUVECs were co-cultured. The ELISA results showed that the TSP4, VEGF and TGF- $\beta$ contents in the supernatant were increased in the TSP4-BMSC and HUVEC co-culture after $48 \mathrm{~h}$. As an angiogenic protein, VEGF induced the effects of angiogenesis after ischaemia [45]. Furthermore, BMSC differentiation into endothelial cells and tube formation through improvement of VEGF receptor expression were demonstrated; in this sense, BMSC treatment will result in angiogenesis via mediating VEGF expression [46-48]. TGF- $\beta$ is a crucial cytokine that stimulates cell proliferation and regulates ECM synthesis [49]. When bound to TGF- $\beta$, the TGF- $\beta$ type II receptor directly recruits and phosphorylates the TGF- $\beta$ type I receptor. Once recruited to the activated TGF- $\beta$ receptor complex, Smad2/3 is phosphorylated and integrates with Smad4 to generate a heterodimeric complex. Subsequently, the Smad complex translocates from the cytoplasm to the nucleus and initiates the expression of downstream target genes [50]. As a result, we examined the TGF- $\beta /$ smad $2 / 3$ signalling pathway. The Western blotting results showed that TGF- $\beta$ and phosphorylated smad2/3 were elevated in the TSP4-BMSC group. Meanwhile, the TGF$\beta /$ smad $2 / 3$ signalling pathway was inhibited after adding signal pathway inhibitors, indicating that TSP4-BMSC indeed activated the TGF- $\beta /$ smad2/3 signalling pathway. Thus, the role of TSP4-BMSC in promoting angiogenesis may be related to TGF- $\beta /$ smad $2 / 3$ signalling pathway activation.

6. The above results indicate that TSP4-BMSCs may promote the secretion of angiogenic factors by HUVECs. The wound healing assay results showed that TSP4-BMSCs could promote the proliferation and migration of HUVECs after co-culture for 24 hours. Moreover, the Western blotting results showed that $\mathrm{p}-\mathrm{Cdc} 42 / \mathrm{Rac} 1$ expression was increased, suggesting that TSP4-BMSCs promoted the proliferation and migration of HUVECs probably by regulating the Cdc42/Rac1 signalling pathway. The arterial ring and tube formation experiments indicated that TSP4-BMSCs could promote angiogenesis and tube formation by HUVECs, and the Western blotting results showed that TSP4BMSCs promoted the expression of angiogenic factors, such as VEGF, Ang-1, MMP9 and MMP2, by endothelial cells. These results further explain that TSP4-BMSCs may play a role by promoting the expression of angiogenic factors both within endothelial cells and extracellularly.

7. To further elucidate the effect of TSP4-overexpressing BMSCs on angiogenesis in the CLI, we established a CLI model in diabetic First, intraperitoneal injection of STZ in rats was used to increase blood glucose and stabilize the level to above $16.7 \mathrm{mmol} / \mathrm{L}$. The femoral artery and important 
branches were ligated to cause extensive ischaemia in the hind limbs of the rats. The limbic activity of the ischaemic side of the rats was unfavourable, the skin temperature was decreased, and gangrene of the ischaemic limbs appeared at 14 days, indicating that the model establishment was successful. Then, TSP4-BMSCs were injected into the ischaemic muscle, and the motor function score was assessed on days 1, 3, 7, 14 and 28 after the operation. The results showed that TSP4BMSC treatment promoted the recovery of motor function in the rats. Immunohistochemistry and immunofluorescence staining were used to assess the expression of cytokines in ischaemic muscle tissue from the rats. The results showed that TSP4-BMSC treatment significantly promoted MMP2, MMP9, Ang-1, vWF and VEGF expression in the rat ischaemic muscle tissue. Meanwhile, new blood vessels can be observed around the ischemic area after TSP4-BMSCs treatment. The above results indicated that TSP4-BMSCs promoted angiogenesis of ischaemic muscle tissue in rats, which was related to vascular growth factor secretion.

8. To summarize, TSP4-overexpressing BMSCs were used for cell transplantation, which improved the effect of local angiogenesis by increasing sustained TSP4 secretion in this study. In addition, these cells amplified the paracrine effect of BMSCs and effectively exerted a synergistic multiplication effect of TSP4 and BMSCs on angiogenesis. Meanwhile, the post-ischaemic microenvironment was improved through the angiogenesis effects of TSP4, which provided the best living space for the proliferation and differentiation of BMSCs to improve the experimental curative effect of lower limb ischaemia and promote the recovery of ischaemic limb motor function. In this process, we innovatively used BMSC as a delivery vehicle rather than a simple stem cell. On the basis of better utilization of the therapeutic effect of stem cells, homing effect of stem cells was used to carry and release therapeutic factors to sites of ischemia, hypoxia and inflammation. Secondly, we flexibly applied the activation effect of smad2 by TSP4, and targeted TSP4 to the ischemic and hypoxic site to avoid side effects and adverse reactions such as tumors caused by excessive activation of TGF- $\beta$ signaling pathway. However, the current study has limitations. First, we do not know whether TSP4BMSCs have other effects on improving the motor function of $\mathrm{CLI}$ in addition to angiogenesis. Second, the specific effect and mechanism of the TSP4-BMSC paracrine function in cell types in addition to endothelial cells should be illustrated in vitro. Third, BMSCs surely have other mechanisms as pluripotent cells that need to be further explored in future experiments.

\section{Conclusions}

Our data illustrate that TSP4-BMSCs can promote endothelial cell proliferation, migration, tube formation and the recovery of motor function in diabetic hind limb ischaemic rats. TSP4-BMSCs have better therapeutic effects than BMSCs.

\section{Methods}

\section{Preparation and characterization of BMSCs}


BMSCs isolated from bone marrow of femurs from 50-60 g male Sprague-Dawley (SD) rats were cultured in Dulbecco's Modified Eagle's Medium: Nutrient Mixture F-12 (DMEM/F-12) containing a lower concentration of glucose (1,000 mg/L), 10\% foetal bovine serum (FBS), and $100 \mathrm{U} / \mathrm{ml}$ of gentamycin. Non-adherent cells were removed by replacing the medium after $24 \mathrm{~h}$. The BMSCs were split $(0.25 \%$ trypsin/1 mM EDTA) and further enriched by passage cultures. To evaluate the BMSC purity, BMSCs at passage 3 were stained with CD44-FITC, CD90-PerCP, CD34-PE, and CD45-Alexa antibodies (Santa Cruz, USA) and characterized by flow cytometry (Becton, Dickinson and Company, USA). The flow cytometry analyses are detailed in the supplementary data section.

\section{Construction of the FT106-tsp4-gfp plasmid and FT106-tsp4 plasmid}

Primers were designed according to the plasmid vector FT106-gfp gene coding region (CDS region) sequence (forward: 5'-GACTACAAAGACCATGACGG-3' and reverse: 5'-AGCTCTGCTTATATAAACCTCCC-3') or plasmid vector FT106-gfp'gene coding region (CDS region) sequence (forward: $5^{\prime}$ -

GTCGACAATCAACCTCTGGATTACA-3' and reverse: 5'- CAGGCCGCTCTCGTCGCT-3') combined with the plasmid pCMV6-tsp4 gene coding region (CDS region) sequence (forward: 5'-

TATATAAGCAGAGCTATGCCGGCCCCACGCGCG-3' and reverse: 5'-

ATGGTCTTTGTAGTCATTATCCAAGCGGTCGAAACTCTGG-3'). The primers were synthesized by

Bioengineering Biotechnology (Shanghai) Co., Ltd. The PCR conditions were 30 reaction cycles consisting of 2 min of denaturation at $94^{\circ} \mathrm{C}, 10 \mathrm{~s}$ of denaturation at $94^{\circ} \mathrm{C}, 30 \mathrm{~s}$ of annealing at $57^{\circ} \mathrm{C}$ and 3 min of annealing at $72{ }^{\circ} \mathrm{C}$, a 5 min extension at $72{ }^{\circ} \mathrm{C}$, a 2 min extension at $94^{\circ} \mathrm{C}$, and 30 reaction cycles of $10 \mathrm{~s}$ of denaturation at $94{ }^{\circ} \mathrm{C}, 30 \mathrm{~s}$ of annealing at $57^{\circ} \mathrm{C}$ and $7 \mathrm{~min}$ and $30 \mathrm{~s}$ of annealing at $72^{\circ} \mathrm{C}$, followed by 5 min of a final extension at $72^{\circ} \mathrm{C}$. The FT106-tsp4-gfp plasmid was digested with the Sall and EcoRI enzymes and the FT106-tsp4 plasmid was digested with the Sall and Ndel enzymes to confirm that the insert was the correct size. Sequencing analysis of the plasmid was completed by Bioengineering (Shanghai) Co., Ltd.

\section{FT106-tsp4-gfp lentivirus preparation and BMSC infection}

The recombinant lentiviral vector was co-transfected with two auxiliary packaging plasmids (psPAX2 and pMD.2G) into 293FT cells. The supernatant was collected and filtered through a $0.45 \mu \mathrm{m}$ membrane after the cells were cultured for $48 \mathrm{~h}$ and $72 \mathrm{~h}$. Finally, the recombinant lentiviral vector (FT106-tsp4-gfp) containing the $t s p 4$ and green fluorescent protein reporter $(g f p)$ genes and the recombinant lentiviral vector (FT106-tsp4) containing the tsp4 gene were obtained. The BMSC infected by the recombinant lentiviral vector (FT106-tsp4-gfp) was used in vitro experiment, and the BMSC infected by the recombinant lentiviral vector (FT106-tsp4) was used in animal experiment.

BMSCs were washed gently twice with PBS before infection, and harvested lentiviruses, $8 \mathrm{mg} / \mathrm{ml}$ of polybutene and DMEM/F-12 were added in proper proportions. After 6 hours, the culture medium (DMEM/F12 $+10 \%$ FBS $+1 \mathrm{~g}$ of GM) was replaced. The infection efficiency was observed within three days. The lentivirus-infected BMSCs ( $0.25 \%$ trypsin/ $1 \mathrm{~mm}$ EDTA) were further enriched by subculture. The 
CD44, CD90, CD45 and CD34 surface markers were evaluated by flow cytometry (Becton, Dickinson and Company, USA). The flow cytometry analysis is detailed in the supplementary data section.

\section{Cellular immunofluorescence staining}

BMSCs and TSP4-BMSCs were plated into 24-well plates $\left(4 \times 10^{5}\right.$ cells per well) and cultured in an incubator overnight. The cells were fixed with $4 \%$ paraformaldehyde for $20 \mathrm{~min}$ after washing twice with PBS and stained with Phalloidin (1:500) for $60 \mathrm{~min}$ and DAPI (1:1000) for $10 \mathrm{~min}$ in the dark. The cells were photographed with a fluorescent inverted microscope (Axio Observer 3, Carl Zeiss AG).

\section{Enzyme-linked immunosorbent assay}

Human umbilical vein endothelial cells (HUVECs, ATCC® CRL-1730) were co-incubated with BMSCs and TSP4-BMSCs respectively in transwell plate, and media (including that from HUVECs alone) were obtained 48 hours later. Various solutions were prepared according to the operating instructions (ELISA kit manual, Beijing Sizhengbai Biotechnology Co., Ltd.). Specimens from the three groups (HUVEC, BMSC + HUVEC, TSP4-BMSC + HUVEC) and different concentrations of the standards were added to the corresponding wells. VEGF, TGF $\beta$ and TSP4 biotinylated antibodies and the corresponding enzyme were added to the respective reaction wells and incubated at $37^{\circ} \mathrm{C}$ for $60 \mathrm{~min}$ and $90 \mathrm{~min}$ after the final wash steps, respectively. The developer was added, and the plate was protected from light for 10-20 min at $37^{\circ} \mathrm{C}$. The optical density at $450 \mathrm{~nm}$ was detected with an enzyme-labelled instrument after stopping the reaction.

\section{Western blotting}

The protein concentration was determined according to the BCA method. The membrane was blocked with $5 \%(\mathrm{w} / \mathrm{v})$ de-fatted milk at room temperature for $1 \mathrm{~h}$, cut into pieces containing different target proteins, and incubated with dilutions of the appropriate primary antibodies, including TSP4 (1:500), VEGF (1:500), Ang-1 (1:1000), MMP9 (1:500), MMP2 (1:500), p-cdc42/Rac1 (1:1000), p-smad2/3 (1:1000) and TGF- $\beta$ (1:1000), at $4^{\circ} \mathrm{C}$

\section{Arterial ring experiment}

The thoracic cavity of adult rats was exposed using surgical tools. The thoracic aorta was isolated, cut into sections of approximately $1 \mathrm{~mm}$ and embedded in 48-well plates coated with Matrigel. The three groups of cell culture supernatants were added to each well, and duplicate wells were set for each group. The cells were cultured in a cell culture incubator, and images were taken using an inverted phase contrast microscope (Axio Observer 3, Carl Zeiss AG) at $72 \mathrm{~h}$. The density of new blood vessels was measured using image analysis software (Image-Pro Plus Version 6.0, USA)

\section{Wound Healing and Tube Formation Assays}


Cultured HUVECs were used to evaluate cell migration with the wound healing assay. During the HUVEC logarithmic growth period, 6-well plates containing confluent cells were scratched in a straight line with a pipette tip to simulate a wound; then, the HUVECs were rinsed 3 times with PBS. Subsequently, the cells were incubated with the three groups of media continuously for $24 \mathrm{~h}$, and wound closure was observed. Photographs were captured at 0 and $24 \mathrm{~h}$ with a phase-contrast microscope (Olympus, Japan). Simultaneously, HUVECs were grown in 96-well plates coated with Matrigel, followed by incubation with conditioned media from the three groups for $24 \mathrm{~h}$. The cells were photographed using a phase-contrast microscope, and the number of branch points was counted to verify the capacity for angiogenesis in each group. The Image-Pro Plus software was applied to quantitatively analyse the density of new blood vessels.

\section{Establishment of the critical limb ischemia (CLI) model and experimental group definition}

The study conforms to the National Institutes of Health Guide for the Care and Use of Laboratory Animals (NIH Publications No. 80-23) revised in 1996 for scientific purposes. This study was also approved by the Ethics Committee of Shenzhen Luohu People's Hospital (ZLNK 04/2017, Shenzhen, China). The rats used in this study were fully qualified with Animal certificate number: SCXK (Yue) 2013-0002 and Animal room license number: SYXK (Yue) 2014-0140. Male SD rats (Guangdong Medical Laboratory Animal Centre, Foshan, Guangdong, China) weighing 80-100 g were used in all experiments. The rats were given 60

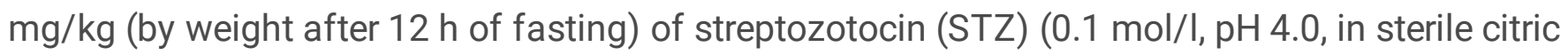
acid/sodium citrate buffer prepared at a dose of $4 \mathrm{mg} / \mathrm{ml}$ ) as a one-time injection in the abdominal cavity. Blood glucose was measured by tail-cutting on days $0,1,3,7,14$ and 28 . The blood glucose concentration was continuously greater than $16.7 \mathrm{mmol} / \mathrm{l}$ after 1 week, indicating that the diabetic rats were successfully modelled. The diabetic rats were anaesthetized with $10 \%(\mathrm{w} / \mathrm{v})$ chloral hydrate $(3.0$ $\mathrm{ml} / \mathrm{kg}$, i.p.), and their body temperature was maintained at $40^{\circ} \mathrm{C}$ with an animal heating pad. $A 1 \mathrm{~cm}$ long incision was made from the midpoint of the left groin to the inside of the knee after routine preparation. The femoral nerve sheath and its branches were exposed through blunt dissection of the subcutaneous tissue. The femoral artery was separated from the large saphenous artery and the external rotatory arteriovenous and femoral arteriovenous muscles. The line was cut after ligation, and the skin was sutured layer by layer. Penicillin was injected at a dose of 100,000 U/piece for 4 days to prevent infection. Sham operated animals were only cut open without ligating blood vessels.

Sixty CLI rats were randomly divided into 3 groups (20 rats per group), including the CLI group, BMSC + CLI group and TSP4-BMSC + CLI group. One millilitre of PBS, BMSC or TSP4-BMSC suspension solution $\left(2 \times 10^{6} \mathrm{cell} / \mathrm{s} / \mathrm{ml}\right)$ was respectively injected into the CLI group, BMSC + CLI group and TSP4-BMSC + CLI group ischaemic peripheral muscle tissue $3 \mathrm{~h}$ after the operation. After claudication in limbs ischemia, hind limbs of the rats will turn to valgus because of limb weakness, which will present an angle compared with normal limbs. Therefore, the rat angle score is an important indicator for judging the degree of lameness in rats. The method of this evaluation is to force the hind limbs of the rats to walk. Based on the long axis of the rat body, the angle of normal claw direction and the angle before the projection of the long axis of the body are measured with the angle measuring instrument, and then the 
angle of the affected limb is measured with the same method. Compared with the normal limb, a larger angle indicates a higher degree of lameness [15]. Basso Beattie Bresnahan (BBB) motor function score was used to evaluate the motor function of each group of rats. After the corresponding treatment of rats, a well-trained independent technician was asked to score the motor function of each group of rats. The score consists of three parts. The first part is $0-7$, which evaluates the joint activities of the hind limbs of the animal. The second part is $8-13$, which evaluates the gait and coordination function of the hind limb, and the third part is 14-21, which is used to evaluate the fine movement of the claw during the exercise, with a total score of 21 points for three items. The higher score indicates the more slight movement disorder [16]. The motor function of each group was evaluated on the days 1, 3, 7, 14, and 28 postinjection. The animals were euthanized by an overdose $(0.30 \mathrm{ml} / 100 \mathrm{~g})$ of ketamine hydrochloride and xylazine hydrochloride (1:1) after the experiment.

\section{Immunohistochemistry and immunofluorescence staining}

On day 28 after the operation, the rats $(n=10)$ in each group were anaesthetized with $10 \%$ chloral hydrate. Muscle tissue in each group was fixed with $4 \%$ paraformaldehyde by transcardial perfusion. Paraffin sections with a $5 \mu \mathrm{m}$ thickness were prepared for immunohistochemistry staining. Prior to all staining procedures, the tissue slices were dewaxed and hydrated with xylene and a reduced ethanol gradient. The samples were rinsed with Dulbecco's phosphate-buffered saline (Sigma, USA) containing $0.01 \%$ Tween 20 and then immersed in $3 \% \mathrm{H}_{2} \mathrm{O}_{2}$ /methanol for $10 \mathrm{~min}$ to inhibit endogenous peroxidase activity after antigen retrieval. To evaluate MMP-2, MMP-9 and Ang-1 expression in the ischaemic muscle, the slices were incubated with rabbit primary antibodies to MMP-2 (1:100), MMP-9 (1:100) and Ang-1 $(1: 200)$ at $4{ }^{\circ} \mathrm{C}$ overnight. Following incubation with a secondary antibody, the sections were coloured with a DAB kit and then stained with haematoxylin as a counterstain. For morphological analysis of the vessels, tissue slices were incubated with primary antibodies against VEGF (1:100) and VWF (1:200) at $4^{\circ} \mathrm{C}$ overnight, followed by the Alexa Fluor 488-labelled goat anti-rabbit $\lg \mathrm{G}(\mathrm{H}+\mathrm{L})$ secondary antibody (Life Technologies, USA) at $37^{\circ} \mathrm{C}$ for $1 \mathrm{~h}$. The nuclei were stained with 4',6-diamidino-2-phenylindole in all images. After the transparent treatment, an image was taken using an inverted phase contrast microscope (Axio Observer 3, Carl Zeiss AG). The Image-Pro Plus software was applied to quantitatively analyse protein expression.

\section{Digital substraction angiography (DSA)}

On day 28 after the operation, the rats $(n=5)$ in each group were anaesthetized with $10 \%$ chloral hydrate. Double hindlimb angiography was performed by intraperitoneal injection of lohexol.

\section{Statistical analysis}

Statistical calculations were performed with Statistical Product and Service Solutions (SPSS) (version 17.0, Chicago, IL, USA) by one-way analysis of variance followed by the least significant difference test for multiple comparisons. Data were expressed as the mean \pm standard deviation (SD). Differences were considered to be statistically significant at $p<0.05$. 


\section{Abbreviations}

TSP4: Thrombospondin-4; BMSCs: bone marrow stromal cells; CLI: critical limb ischemia; HUVECs: human umbilical vein endothelial cells; VEGF: Vascular endothelial growth factor; vWF: Von Willebrand factor; TGF- $\beta$ : transforming growth factor- $\beta$; DSA: digital substraction angiography; ASO: arteriosclerosis obliterans; TAO: thromboangiitis obliterans; CDV: collagen disease-associated vasculitis; ECM: extracellular matrix; SD: Sprague-Dawley; DMEM/F-12: Dulbecco's Modified Eagle's Medium: Nutrient Mixture F-12; FBS: foetal bovine serum; STZ: streptozotocin; BBB: Basso, Beattie, Bresnahan; PGI2: prostaglandin I2; TACT: Therapeutic Angiogenesis by Cell Transplantation; BM-MNC: bone-marrow derived monocytes; IBZ: ischaemic boundary zone; SDF1: stem cell homing factor; HIF-1: hypoxia inducible factor-1

\section{Declarations}

\section{Ethics approval and consent to participate}

All procedures involving animals were approved by the Ethics Committee of Shenzhen Luohu People's Hospital (ZLNK 04/2017, Shenzhen, China).

\section{Consent for publication}

Not applicable.

\section{Competing interests}

The authors declare that they have no competing interests.

\section{Acknowledgements}

The authors thank the Department of Pathology in Shenzhen Luohu People's Hospital for the rat tissue section work.

\section{Authors' contributions}

TL designed the experimental. QZ and XW1 carried out most of the experiments. FZ, XS and TW participated in the design of the study and helped experimental development. QZ drafted the manuscript. 
YW, XW2, MZ, ZL and BL conceived, coordinated and provided financial support for the study. All authors have read and approved the final version of the manuscript.

\section{Funding}

This study was supported by grants from Innovation of Science and Technology Commission of Shenzhen (project No. KQJSCX20170331160008397, No. JCYJ20170412155231633, No. GGFW2016030117123665 and No. JCYJ20170307171034705) and Project funded by China Postdoctoral Science Foundation (2018M641696). These funding bodies coordinated and provided financial support for the study.

\section{Availability of data and materials}

All data generated or analysed during this study are included in this published article and its supplementary information files.

\section{References}

[1] Kondo K, Yanishi K, Hayashida R, Shintani S, Shibata R, Murotani K, Ando M, Mizuno M, Fujiwara T, Murohara T, Matoba S; TACT Follow-up Study Investigators. Long-Term Clinical Outcomes Survey of Bone Marrow-Derived Cell Therapy in Critical Limb Ischemia in Japan. Circ J. 2018;82:1168-78.

[2] Slovut DP, Sullivan TM. Critical limb ischemia: medical andsurgical management. Vasc Med. 2008;13(3):281-91.

[3] Hankey GJ, Norman PE, Eikelboom JW. Medica treatment of peripheralarterial disease. JAMA-J AM MED ASSOC. 2006;295(5):547-53.

[4] Neale JPH, Pearson JT, Katare R, Schwenke DO. Ghrelin, MicroRNAs, and critical limb ischemia: Hungering for a novel treatment option. Front Endocrinol (Lausanne). 2017;8:350.

[5] Norgren L, Hiatt WR, Dormandy JA, Nehler MR, Harris KA, Fowkes FGR. Inter-society consensus for the management of peripheral arterial disease (TASC II). J Vasc Surg, 2007;45(1): S5-S67.

[6] Annex BH. Therapeutic angiogenesis for critical limb ischaemia. Nat Rev Cardiol. 2013;10(7): 387-96.

[7] Li JY, Yang XY, Wang XF, Jia X, Wang ZJ, Deng AP, Bai XL, Zhu L, Li BH, Feng ZB, Li Y, Wang L, Jin S. Siglec-5 is a novel marker of critical limb ischemia in patients with diabetes. Sci Rep. 2017;7(1):11272.

[8] Höckel M, Schlenger K, Doctrow S, Kissel T, Vaupel P. Therapeutic angiogenesis. Arch Surg. 1993;128(4):423-429. 
[9] Firoozi S, Pahlavan S, Ghanian MH, Rabbani S, Barekat M, Nazari A, Pakzad M, Shekari F, Hassani SN, Moslem F, Lahrood FN, Soleimani M, Baharvand H. Mesenchymal stem cell-derived extracellular vesicles alone or in conjunction with a SDKP-conjugated self-assembling peptide improve a rat model of myocardial infarction. Biochem Biophys Res Commun. 2020;pii:S0006-291X(20)30269-2.

[10] Chandra A, Jahangiri A, Chen W, Nguyen AT, Yagnik G, Pereira MP, Jain S, Garcia JH, Shah SS, Wadhwa H, Joshi RS, Weiss J, Wolf KJ, Lin JG, Müller S, Rick JW, Diaz AA, Gilbert LA, Kumar S, Aghi MK. Clonal ZEB1-driven mesenchymal transition promotes targetable oncologic anti-angiogenic therapy resistance. Cancer Res. 2020;pii: canres.1305.2019.

[11] Kirana S, Stratmann B, Prante C, Prohaska W, Koerperich H, Lammers D, et al. Autologous stem cell therapy in the treatment of limb ischaemia induced chronic tissue ulcers of diabetic foot patients. Int $\mathrm{J}$ Clin Pract. 2012;66(4):384-93.

[12] Chu DT, Phuong TNT, Tien NLB, Tran DK, Thanh VV, Quang TL, Truong DT, Pham VH, Ngoc VTN, ChuDinh T, Kushekhar K. An Update on the Progress of Isolation, Culture, Storage, and Clinical Application of Human Bone Marrow Mesenchymal Stem/Stromal Cells. Int J Mol Sci. 2020;21(3).

[13] Adams JC, Lawler J. The thrombospondins. Int J Biochem Cell Biol. 2004;36(6):961-8.

[14] Muppala S, Frolova E, Xiao R, Krukovets I, Yoon S, Hoppe G, et al. Proangiogenic Properties of Thrombospondin-4. Arterioscler Thromb Vasc Biol. 2015;35(9):1975-86.

[15] Hasegawa A, Takahashi M, Satomi K, Ohne H, Takeuchi T, Sato S, Ichimura S. Mechanism of Forelimb Motor Function Restoration after Cervical Spinal Cord Hemisection in Rats: A Comparison of Juveniles and Adults. Behav Neurol. 2016;1035473.

[16] Basso DM, Beattie MS, Bresnahan JC. A sensitive and reliable locomotor rating scale for open field testing in rats. J Neurotrauma. 1995;12(1):1-21.

[17] Spiliopoulos S, Theodosiadou V, Katsanos K, Kitrou P, Kagadis GC, Siablis D, Karnabatidis D. Longterm clinical outcomes of infrapopliteal drug-eluting stent placement for critical limb ischemia in diabetic patients. J Vasc Interv Radiol 2015;26:1423-30.

[18] Kimura A, Kobayashi Y, Takahashi M, Ohbuchi N, Kitamura H, Nakamura T, Satoh M, Sasaoka T, Hiroi $\mathrm{S}$, Arimura T, et al. MICA gene polymorphism in Takayasu's arteritis and Buerger's disease. Int J Cardiol. 1998;66 (Suppl 1): S107-13; discussion S115.

[19] Sadik NA, Mohamed WA, Ahmed MI. The association of receptor of advanced glycated end products and inflammatory mediators contributes to endothelial dysfunction in a prospective study of acute kidney injury patients with sepsis. Mol Cell Biochem. 2012;359(1-2):73-81.

[20] Isner JM, Pieczek A, Schainfeld R, Blair R, Haley L, Asahara T, Rosenfield K, Razvi S, Walsh K, Symes JF. Clinical evidence of angiogenesis after arterial gene transfer of phVEGF165 in patient with ischaemic 
limb. Lancet. 1996;348(9024):370-4.

[21] Amann B, Luedemann C, Ratei R, Schmidt-Lucke JA. Autologous bone marrow cell transplantation increases leg perfusion and reduces amputations in patients with advanced critical limb ischemia due to peripheral artery disease. Cell Transplant. 2009;18(3):371-80.

[22] Horie T, Onodera R, Akamastu M, Ichikawa Y, Hoshino J, Kaneko E, Iwashita C, Ishida A, Tsukamoto T, Teramukai S, Fukushima M, Kawamura A; Japan Study Group of Peripheral Vascular Regeneration Cell Therapy (JPRCT). Long-term clinical outcomes for patients with lower limb ischemia implanted with GCSF-mobilized autologous peripheral blood mononuclear cells. Atherosclerosis. 2010;208(2):461-6.

[23] Franz RW, Shah KJ, Pin RH, Hankins T, Hartman JF, Wright ML. Autologous bone marrow mononuclear cell implantation therapy is an effective limb salvage strategy for patients with severe peripheral arterial disease. J Vasc Surg. 2015;62(3):673-80.

[24] Tateishi-Yuyama E, Matsubara H, Murohara T, Ikeda U, Shintani S, Masaki H, Amano K, Kishimoto Y, Yoshimoto K, Akashi H, Shimada K, Iwasaka T, Imaizumi T; Therapeutic Angiogenesis using Cell Transplantation (TACT) Study Investigators. Therapeutic angiogenesis for patients with limb ischaemia by autologous transplantation of bone-marrow cells: A pilot study and a randomised controlled trial. Lancet. 2002;360(9331):427-35.

[25] Matoba S, Tatsumi T, Murohara T, Imaizumi T, Katsuda Y, Ito M, Saito Y, Uemura S, Suzuki H, Fukumoto S, Yamamoto Y, Onodera R, Teramukai S, Fukushima M, Matsubara H; TACT Follow-up Study Investigators. Long-term clinical outcome after intramuscular implantation of bone marrow mononuclear cells (Therapeutic Angiogenesis by Cell Transplantation [TACT] trial) in patients with chronic limb ischemia. Am Heart J. 2008;156(5):1010-8.

[26] Idei N, Soga J, Hata T, Fujii Y, Fujimura N, Mikami S, Maruhashi T, Nishioka K, Hidaka T, Kihara Y, Chowdhury M, Noma K, Taguchi A, Chayama K, Sueda T, Higashi Y. Autologous bone-marrow mononuclear cell implantation reduces long-term major amputation risk in patients with critical limb ischemia: A comparison of atherosclerotic peripheral arte- rial disease and Buerger disease. Circ Cardiovasc Interv. 2011;4(1):15-25.

[27] Kondo K, Yanishi K, Hayashida R, Shintani S, Shibata R, Murotani K, Ando M, Mizuno M, Fujiwara T, Murohara T, Matoba S; TACT Follow-up Study Investigators. Long-Term Clinical Outcomes Survey of Bone Marrow-Derived Cell Therapy in Critical Limb Ischemia in Japan. Circ J. 2018;82(4):1168-78.

[28] Guo J, Guo L, Cui S, Tong Z, Dardik A, Gu Y. Autologous bone marrow-derived mononuclear cell therapy in Chinese patients with critical limb ischemia due to thromboangiitis obliterans: 10-year results. Stem Cell Res Ther. 2018;9(1):43.

[29] Ferrari G, Cusella-De Angelis G, Coletta M, Paolucci E, Stornaiuolo A, Cossu G, et al. Muscle regeneration by bone marrow-derived myogenic progenitors. Science. 1998;279(5356):1528-30. 
[30] Shichinohe H, Yamauchi T, Saito H, Houkin K, Kuroda S. Bone marrow stromal cell transplantation enhances recovery of motor function after lacunar stroke in rats. Acta Neurobiol Exp (Wars). 2013;73(3):354-63.

[31] Wei L, Fraser JL, Lu ZY, Hu X, Yu SP. Transplantation of hypoxia preconditioned bone marrow mesenchymal stem cells enhances angiogenesis and neurogenesis after cerebral ischemia in rats. Neurobiol Dis. 2012;46(3):635-45.

[32] Chen J, Venkat P, Zacharek A, Chopp M. Neurorestorative therapy for stroke. Front Hum Neurosci. 2014;8:382.

[33] Pavlichenko N, Sokolova I, Vijde S, Shvedova E, Alexandrov G, Krouglyakov P, et al. Mesenchymal stem cells transplantation could be beneficial for treatment of experimental ischemic stroke in rats. Brain Res. 2008;1233:203-13.

[34] Onteniente B, Polentes J. Regenerative medicine for stroke - are we there yet? Cerebrovasc Dis. 2011;31(6):544-51.

[35] Adams JC. Thrombospondins: multifunctional regulators of cell interactions. Annu Rev Cell Dev Biol. 2001;17:25-51.

[36] Tymchuk CN, Hartiala J, Patel PI, Mehrabian M, Allayee H. Nonconventional genetic risk factors for cardiovascular disease. Curr Atheroscler Rep. 2006;8(3):184-92.

[37] Forslow A, Liu Z, Sundqvist KG. Receptor communication within the lymphocyte plasma membrane: a role for the thrombospondin family of matricellular proteins. Cell Mol Life Sci. 2007;64(1):66-76.

[38] Bornstein P. Thrombospondins as matricellular modulators of cell function. J Clin Invest. 2001;107(8):929-34.

[39] DiPietro LA, Nebgen DR, Polverini PJ. Downregulation of endothelial cell thrombospondin 1 enhances in vitro angiogenesis. J Vasc Res. 1994;31(3):178-85.

[40] Frolova EG, Sopko N, Blech L, Popovic ZB, Li J, Vasanji A, et al. Thrombospondin-4 regulates fibrosis and remodeling of the myocardium in response to pressure overload. FASEB J. 2012;26(6):236373.

[41] Frolova EG, Pluskota E, Krukovets I, Burke T, Drumm C, Smith JD, et al. Thrombospondin-4 regulates vascular inflammation and atherogenesis. Circ Res. 2010;107(11):1313-25.

[42] Raman P, Krukovets I, Marinic TE, Bornstein P, Stenina OI. Glycosylation mediates up-regulation of a potent antiangiogenic and proatherogenic protein, thrombospondin-1, by glucose in vascular smooth muscle cells. J Biol Chem. 2007;282(8):5704-14. 
[43] Pluskota E, Stenina OI, Krukovets I, Szpak D, Topol EJ, Plow EF. Mechanism and effect of thrombospondin-4 polymorphisms on neutrophil function. Blood. 2005;106(12):3970-8.

[44] Stenina OI, Desai SY, Krukovets I, Kight K, Janigro D, Topol EJ, et al. Thrombospondin-4 and its variants: expression and differential effects on endothelial cells. Circulation. 2003;108(12):1514-9.

[45] Sun Y, Jin K, Xie L, Childs J, Mao XO, Logvinova A, et al. VEGF-induced neuroprotection, neurogenesis, and angiogenesis after focal cerebral ischemia. J Clin Invest. 2003;111(12):1843-51.

[46] Cui X, Chopp M, Zacharek A, Roberts C, Lu M, Savant-Bhonsale S, et al. Chemokine, vascular and therapeutic effects of combination Simvastatin and BMSC treatment of stroke. Neurobiol Dis. 2009;36(1):35-41.

[47] Xu J, Liu X, Chen J, Zacharek A, Cui X, Savant-Bhonsale S, et al. Simvastatin enhances bone marrow stromal cell differentiation into endothelial cells via notch signaling pathway. Am J Physiol Cell Physiol. 2009;296(3):C535-43.

[48] Deng YB, Ye WB, Hu ZZ, Yan Y, Wang Y, Takon BF, et al. Intravenously administered BMSCs reduce neuronal apoptosis and promote neuronal proliferation through the release of VEGF after stroke in rats. Neurol Res. 2010;32(2):148-56.

[49] Barrientos S, Stojadinovic O, Golinko MS, Brem H, Tomic-Canic M. Growth factors and cytokines in wound healing. Wound Repair Regen. 2008;16(5):585-601.

[50] Kryger ZB, Sisco M, Roy NK, Lu L, Rosenberg D, Mustoe TA. Temporal expression of the transforming growth factor-Beta pathway in the rabbit ear model of wound healing and scarring. $\mathrm{J} A \mathrm{~m}$ Coll Surg. 2007;205(1):78-88.

\section{Supplemental Figure Legend}

The phenotype identification of BMSCs and TSP4-BMSCs. (a) BMSCs from passage 3 were incubated with fluorescence-conjugated antibodies including CD44-FITC, CD90-PerCP, CD34-PE, CD45-Alexa and PBS. The positive expression of CD44 and CD90 were 98.34 and $99.88 \%$, and negative identifications of CD34 and CD45 were 4.81 and $1.81 \%$, respectively. (b) TSP4-BMSCs were incubated with fluorescenceconjugated antibodies including CD44-FITC, CD90-PerCP, CD34-PE, CD45-Alexa and PBS. The positive expression of CD44 and CD90 were 93.52 and $98.78 \%$, and negative identifications of CD34 and CD45 were 5.85 and $4.36 \%$, respectively.

\section{Figures}




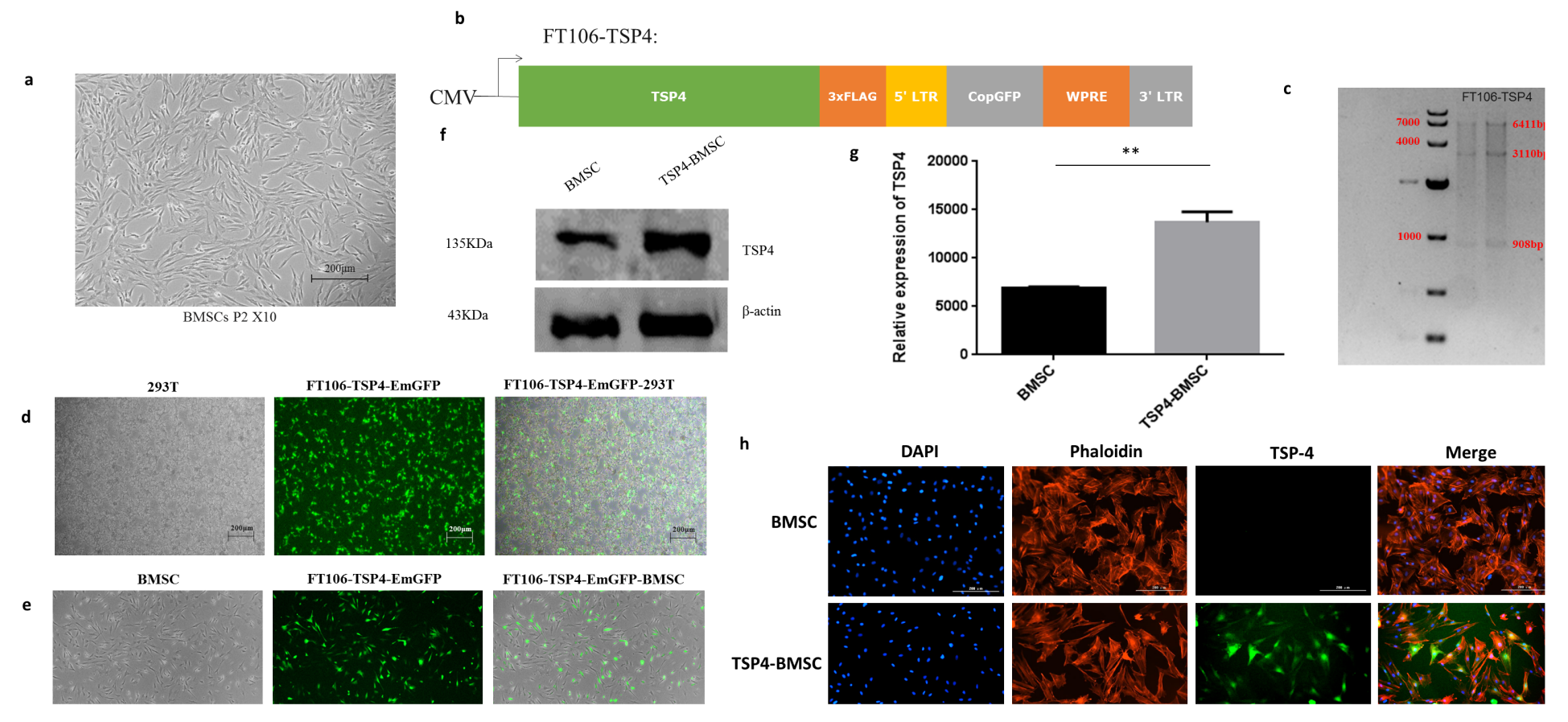

Figure 1

Construction of FT106-tsp4-gfp plasmid and expression of target protein of TSP4. (a) BMSC The morphology of BMSC. The cells are uniform and grow in whirlpool, radial, or parallel patterns in passage 2 (Magnification, $\times 100$ ). (b) Schematic illustration of the structure of FT106-tsp4-gfp. (c) Sall and EcoRI double digestion of two recombinant plasmids into $6411,3110,908$ bps size fragments. The positions of the 7000, 4000, 1000 bps size marker are indicated to the left of the panel. (d) Plasmids of psPAX2, pMD.2G and FT106-tsp4 were transfected into 293FT cells (green) in appropriate proportions. The positive rate of transfection was $91.25 \% \pm 0.0078$. (e) FT106-tsp4-gfp lentivirus infects BMSCs (green). The positive rate of infection was $65.49 \% \pm 0.0145$. (f) Western blot tested the expressions of TSP4 secreted by BMSC and TSP4-BMSC. (g) Western blot results for TSP4 and quantitative analysis. Data are expressed as mean \pm SD. ${ }^{* *} p<0.01$ (h) Fluorescent staining of TSP4-BMSC and BMSC. (the nucleus-blue, the cytoskeleton-red, TSP4 protein-green). 
a

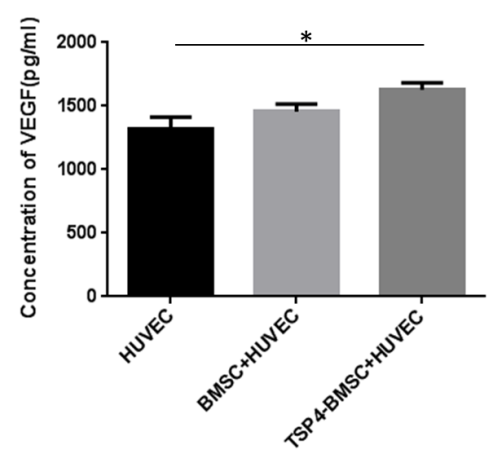

d

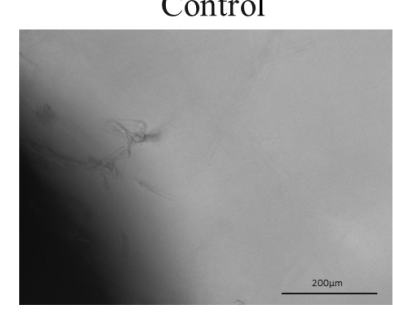

Control

f

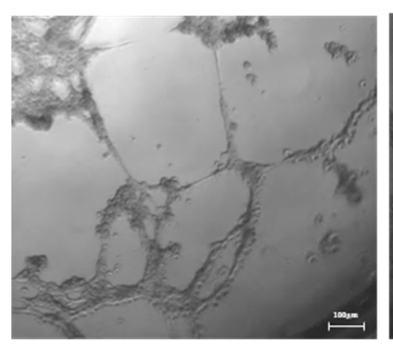

h
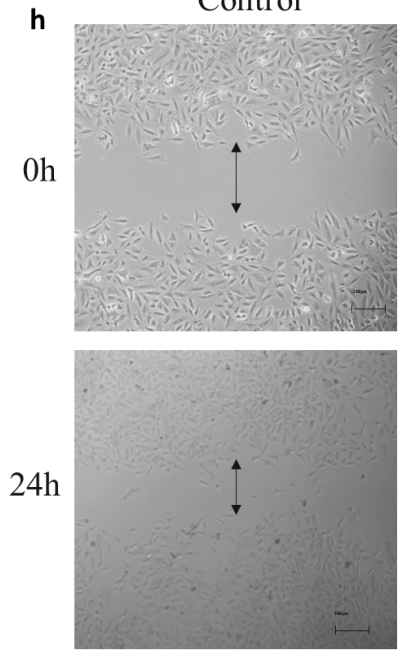

b

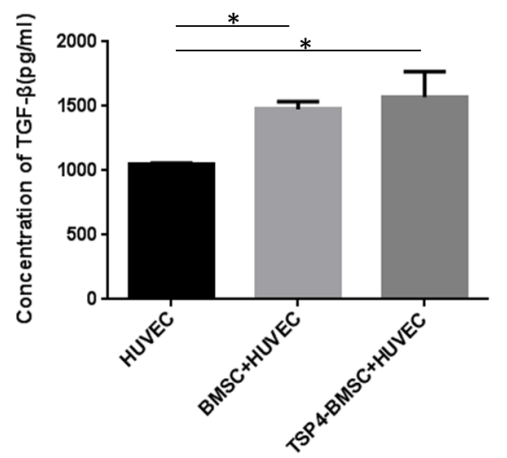

BMSC

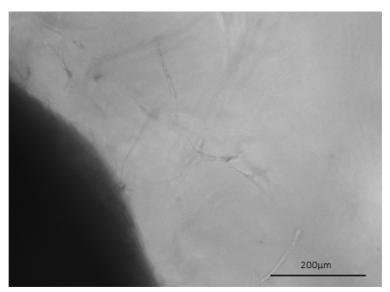

BMSC

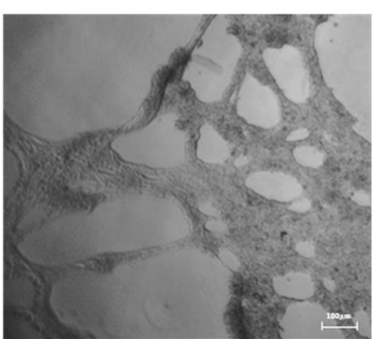

BMSC
TSP4-BMSC

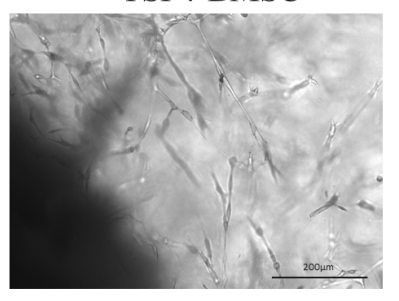

TSP4-BMSC

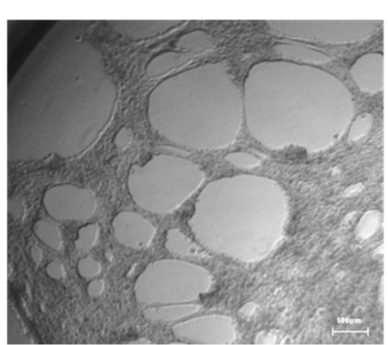

TSP4-BMSC

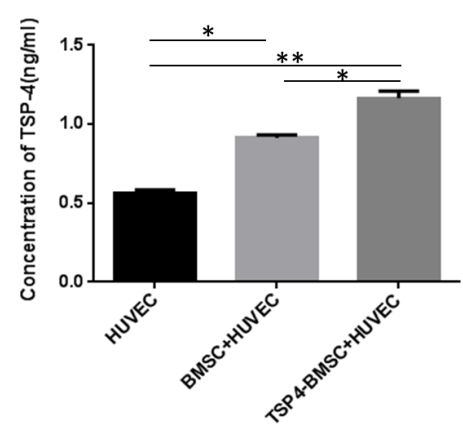

e

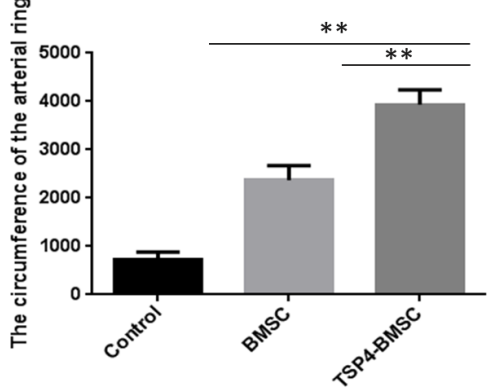

g

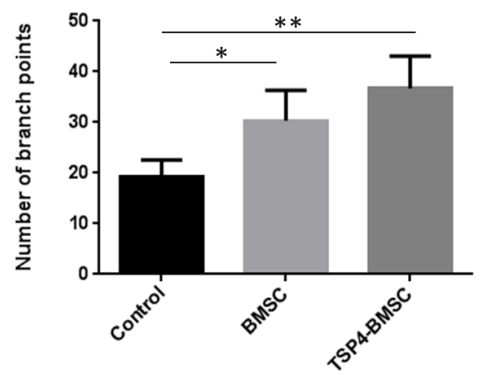

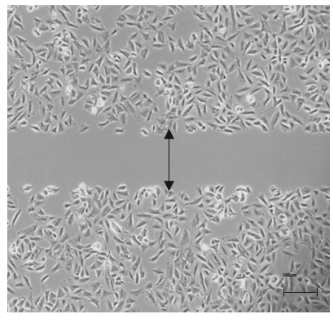
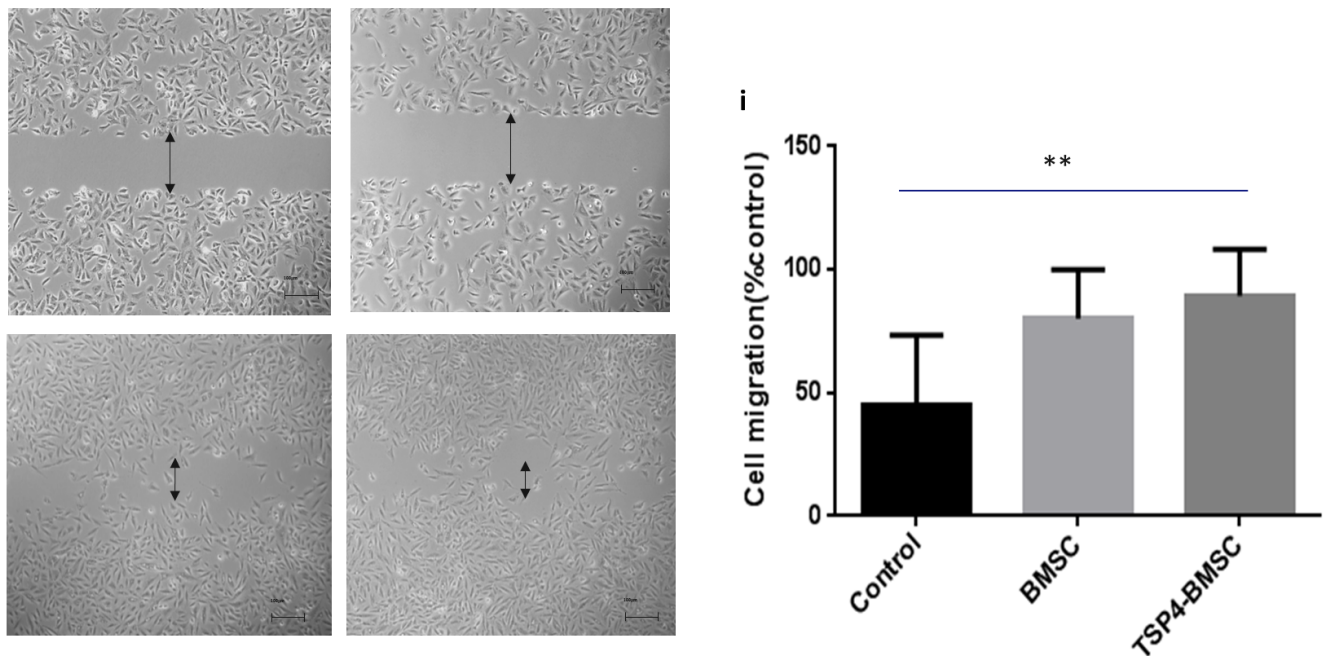

Figure 2

Effect of TSP4-BMSC on angiogenesis of HUVEC. $(a, b, c)$ The content of VEGF, TGF- $\beta$ and TSP4 in the supernatant incubated with HUVEC and TSP4-BMSC was detected by ELISA. Data are expressed as mean \pm SD. ${ }^{*} p<0.01,{ }^{\star} p<0.05$. (d, e) The effect of TSP4-BMSC on angiogenesis was examined by arterial ring experiment. Data are expressed as mean \pm SD. ${ }^{*} p<0.01$. (f, g) Effect of TSP4-BMSC on tube formation of HUVEC in 24h. Data are expressed as mean \pm SD. ${ }^{* *} p<0.01$, ${ }^{*} p<0.05$. (h, i) Effect of TSP4-BMSC on 
proliferation and migration of HUVEC in $24 \mathrm{~h}$ by wound healing test. Data are expressed as mean \pm SD. $\star * p<0.01$.

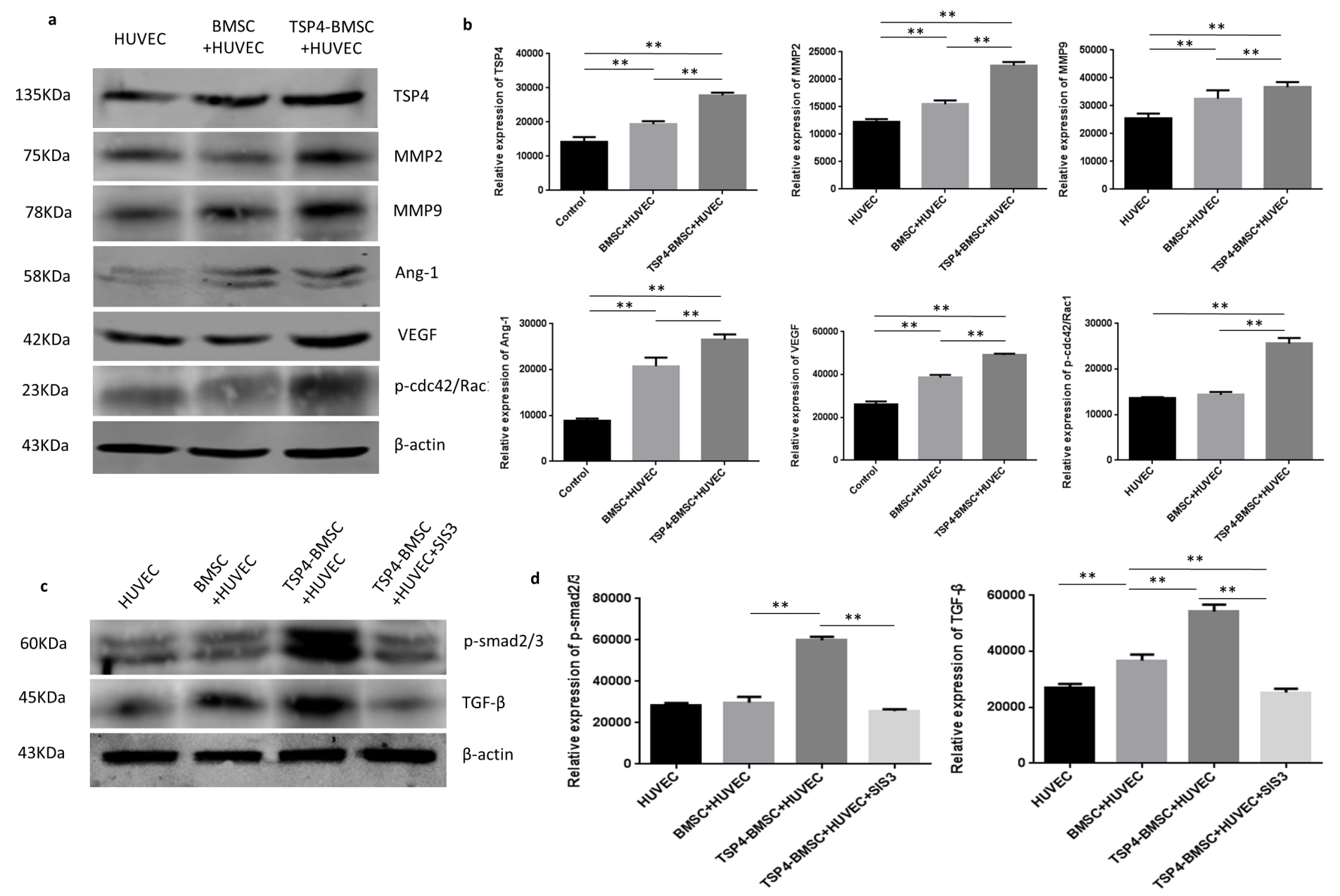

\section{Figure 3}

HUVEC derived angiogenic factors expressions and activated TGF- $\beta /$ smad $2 / 3$ signaling pathway incubated with TSP4-BMSC by western blot assay. (a) Western blot tested the expressions of HUVEC derived-TSP4, MMP2, MMP9, Ang-1, VEGF and p-Cdc42/Rac1 in three groups (HUVEC, BMSC+HUVEC and TSP4-BMSC+HUVEC) respectively. (b) Representative western blot results for TSP4, MMP2, MMP9, Ang-1, VEGF and p-cdc42/Rac1 and quantitative analysis at 48h after co-incubation. Data are expressed as mean \pm SD. ${ }^{* *} p<0.01$. (c) Representative western blot results for $p$-smad $2 / 3$ and TGF- $\beta$ in four groups (HUVEC, BMSC+HUVEC, TSP4-BMSC+HUVEC and TSP4-BMSC+HUVEC+SIS3) were shown; (d) quantitative analysis was presented. Data are expressed as mean \pm SD. ${ }^{\star *} p<0.01$. 


$$
\text { a }
$$

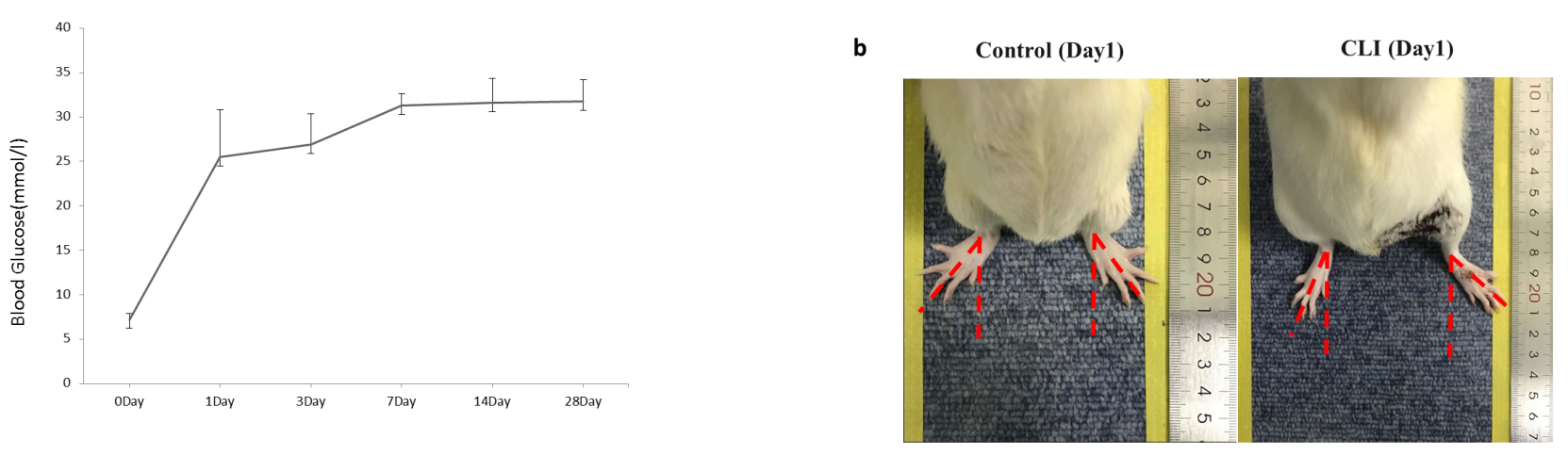

c
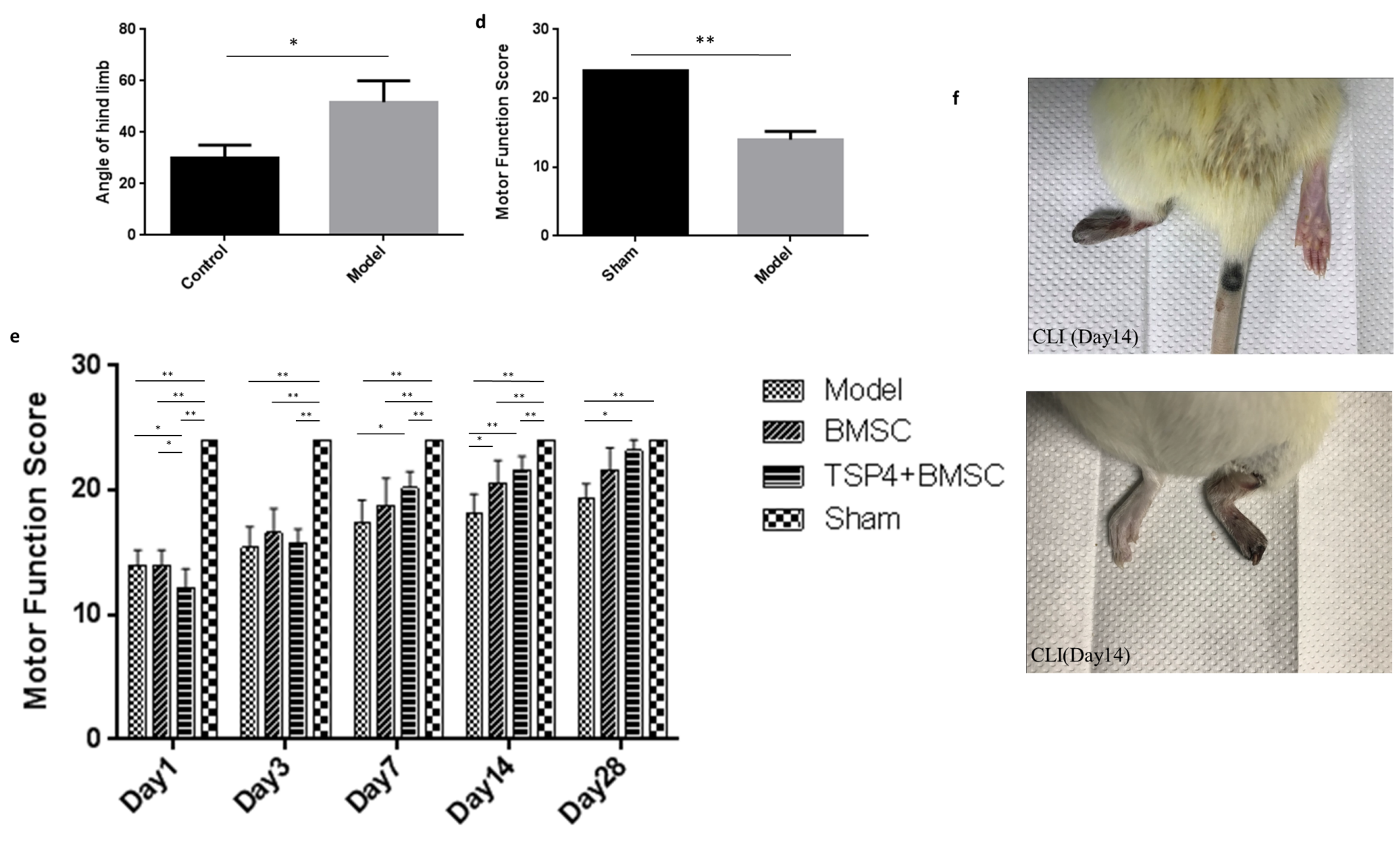

Figure 4

Establishment of CLI model in diabetic rats and evaluation of motor function score. (a) Changes of blood glucose in rats from day 0 to day 28 after STZ administration. The blood glucose level increased to $25 \mathrm{mmol} / \mathrm{I}$ after the first day of STZ injection, and then stabilized above $25 \mathrm{mmol} / \mathrm{l}$. (b) Schematic diagram of hindlimb angle in CLI model on 1th day. (c) Quantitative analysis of hind limb angle. Data are expressed as mean $\pm S D$. ${ }^{*} p<0.05$. (d) Motor function score of rats on the first day after operation. Data are expressed as mean \pm SD. ${ }^{*} p<0.01$. (e) Motor function score of rats on the 1th, 3th, 7th, 14th and 28th day after operation in four groups (Sham, Model, BMSC and TSP4-BMSC). Data are expressed as mean \pm SD. ${ }^{*} p<0.05,{ }^{*} p<0.01$. (f) Schematic diagram of CLI model rats on the 14th day after operation. 


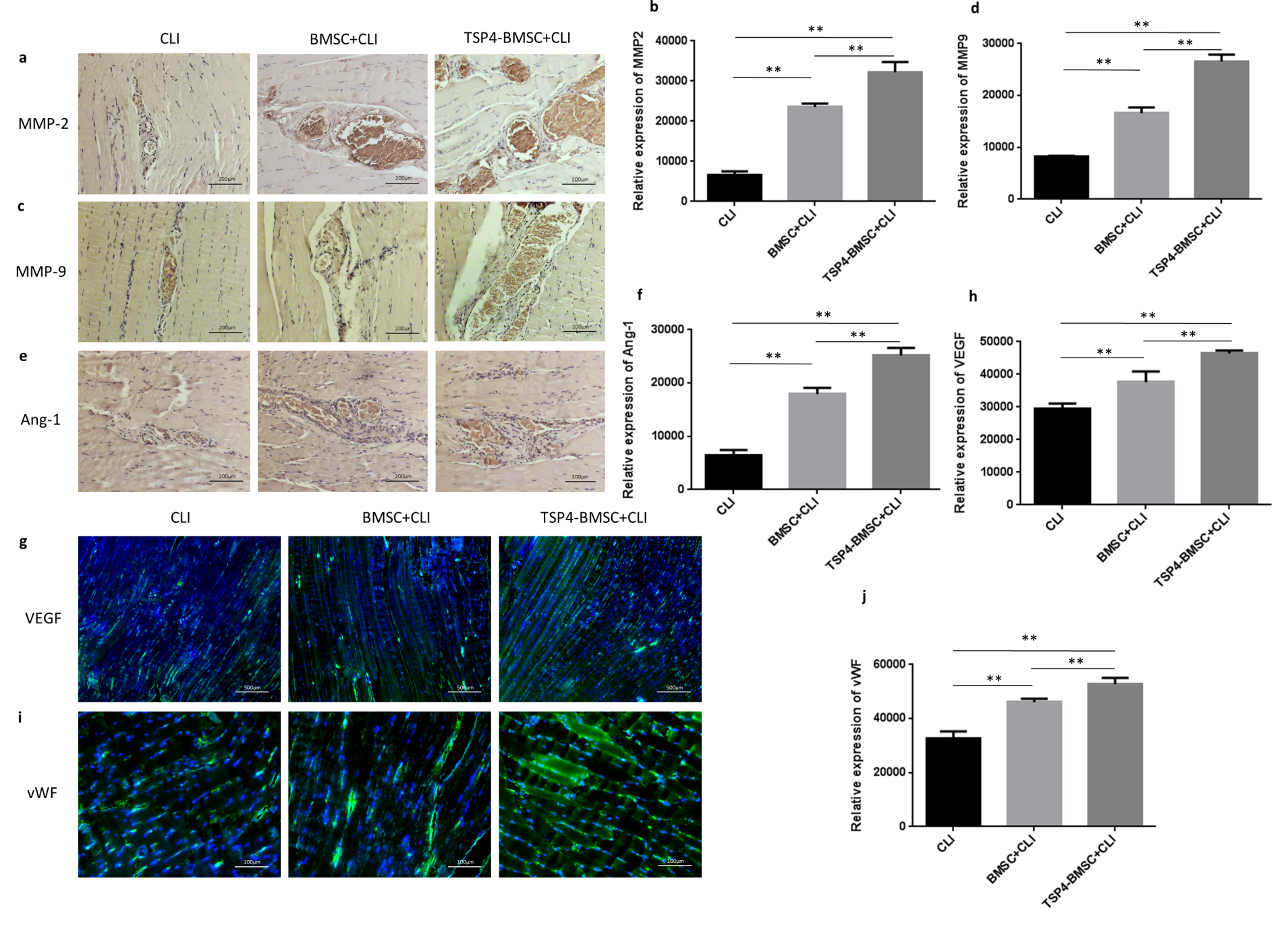

Figure 5

TSP4-BMSC enhanced angiogenesis through promoted MMP2, MMP9, Ang-1, VEGF and VWF expressions in CLI model. (a, b, c, d, e, f) Immunohistochemistry staining images with MMP2, MMP9 and Ang-1 were presented and positive signals were analyzed on 28th day. Data are expressed as mean \pm SD. ${ }^{* *} p<0.01$. The experiment was repeated for 3 times, and representative pictures are shown. Scale bar $200 \mu \mathrm{m} .(\mathrm{g}, \mathrm{h}, \mathrm{i}$, j) Immunofluorescence staining images of VEGF (green) (Scale bar $500 \mu \mathrm{m}$ ) and vWF-vessles (green) (Scale bar $100 \mu \mathrm{m}$ ) were presented on 28th day, vWF positive vascular density, as well as relative expression of VEGF were quantitated. Data are expressed as mean \pm SD. ${ }^{\star} p<0.05,{ }^{*} p<0.01$. The experiment was repeated for 3 times, and representative pictures are shown. 

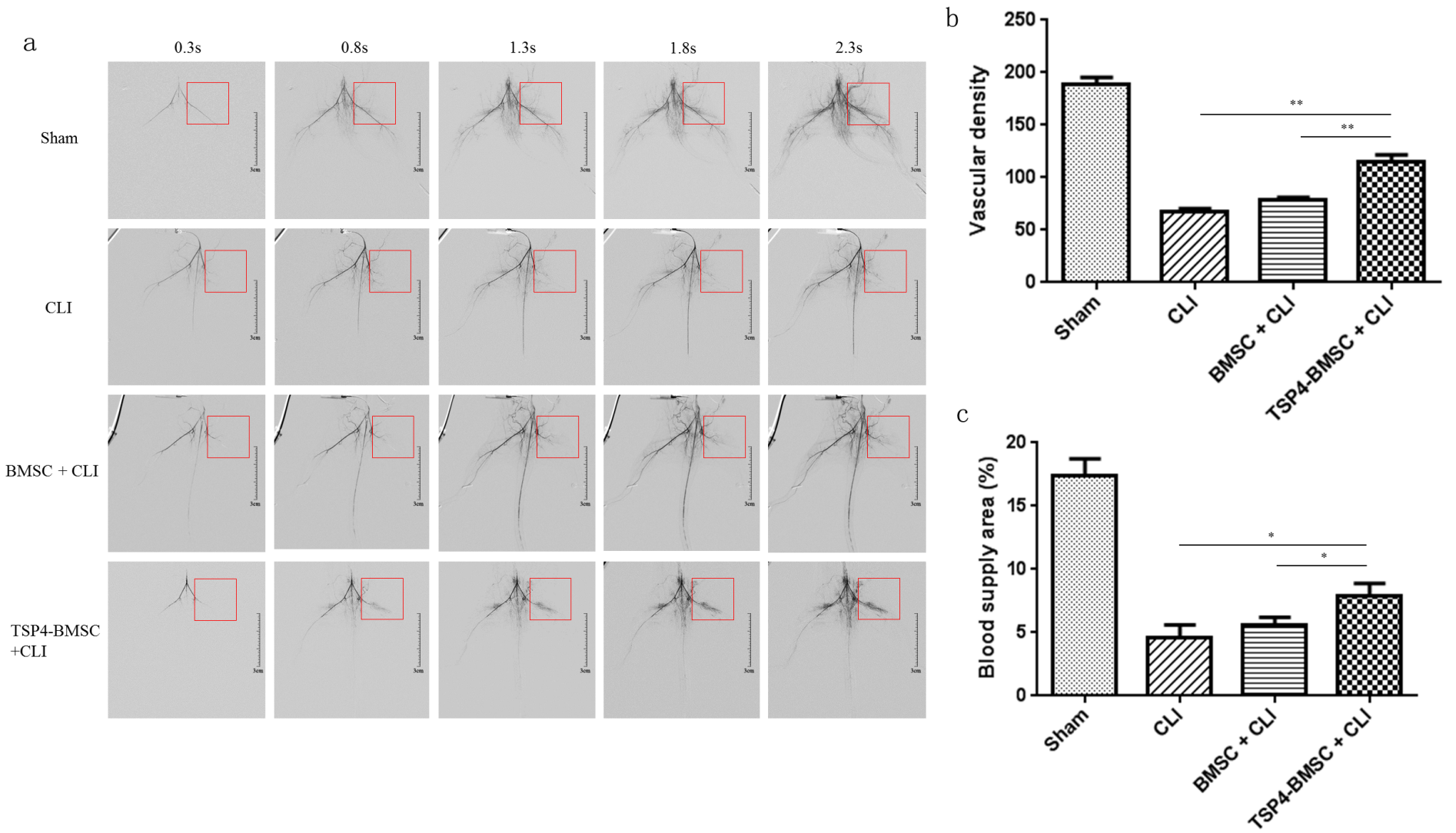

\section{Figure 6}

TSP4-BMSC increases vascular density and blood supply area around the ischemic area. (a) DSA image of double hindlimb in rats on the 28th day after operation in four groups (Sham, CLI, BMSC + CLI and TSP4-BMSC + CLI) (Scale bar $3 \mathrm{~cm}$ ). (b) Vascular density were quantitated. Data are expressed as mean $\pm S D$. ${ }^{\star \star} p<0.01$. The experiment was repeated for 3 times, and representative pictures are shown. (c) Blood supply area were quantitated. Data are expressed as mean \pm SD. ${ }^{\star} p<0.05$. The experiment was repeated for 3 times, and representative pictures are shown.

\section{Supplementary Files}

This is a list of supplementary files associated with this preprint. Click to download.

- SupFigure.tif

- NC3RsARRIVEGuidelinesChecklist.docx 